\title{
Embedding, covert movement, and intervention in Kathmandu Newari
}

\author{
Borui Zhang \& Dustin A. Chacón*
}

\begin{abstract}
In this paper, we explore the syntax of $w h$-dependencies in Newari (Sino-Tibetan). We examine the patterns of intervention and island effects in wh-in-situ configurations, and we find that sensitivity to these constraints often co-occur. We thus argue that Newari permits $w h$-operators to either covertly move to fix their scope, or may take scope in-situ via focus alternative composition analysis. Additionally, we argue that clausal complements to verbs ("verbal argument CPs") may be islands for covert movement in this language.
\end{abstract}

Keywords. Newari; movement; verbal-argument CPs; wh-phrases; scope; LF; covert movement

\section{Introduction.}

1.1. TheORETICAL BACKGROUND. In some languages, wh-operators in simple interrogatives overtly move, and in others, the wh-operator stays in-situ. In languages like English, the wh-operator moves from the base position to the Spec, CP position to take sentential scope, shown in (1). In languages like Newari, as in (2), the wh-operator may take sentential scope in-situ.

(1) What did Ram eat $t_{\mathrm{i}}$ ?

(English)

(2) Rām-na chu na-la?

Ram-ERG what eat-PST

'What did Ram eat?'

(Newari)

Broadly, there are two main analyses of how in-situ wh-operators take wide scope without overt movement. One approach posits covert movement of the wh-operator (Huang 1982, Soh 2005, Yang 2012). This approach suggests that the wh-operator stays in-situ on the surface syntax as in (3a), but moves to the Spec,CP position at LF, as in (3b).

(3) a. Surface syntax: [СР [Tе Ram what ate]

b. $\underline{\underline{\mathrm{LF}}:\left[\mathrm{CP} \boldsymbol{\boldsymbol { w h a t } _ { \mathrm { i } }}[\mathrm{TP}\right.} \operatorname{Ram} t_{\mathrm{i}}$ ate] ]

Covert movement (CM) analyses prima facie predict that wh-in-situ configurations should exhibit the same properties as overt movement, e.g., island sensitivity. In fact, island sensitivity is observed in wh-in-situ configurations. For example, in Mandarin Chinese, in-situ wh-operators display sensitivity to the Complex NP Constraint (Huang 1982, Bayer 2006, Cheng 2009). As shown in (4), the adverbial wh-phrase weishenme 'why' cannot covertly move out the DP, and thus fails to take sentential scope.

* Qiaofeng xihuang [DP [CP Botong weishenme xie de] shu] Qiaofeng like Botong why written DE book 'For what reason $x$, Qiaofeng likes the book that Botong wrote for $x$ ?'

(Mandarin, Huang 1982)

* We thank Jason Overfelt, Claire Halpert, Hadas Kotek, and Michael Yoshitaka Erlewine for their feedback on this project. We also thank our consultant, Tijala Chitrakar. All mistakes are our own. 
Another account of wh-in-situ configurations is the focus alternatives composition analysis (FA). On this approach, $w h$-phrases are focus elements, and are interpreted by computing the focus semantic alternatives of the sentence (Beck 2006, Hamblin 1973, Karttunen 1977). On this account, wh-phrases have no ordinary semantic value, but instead "shift" the semantic value via $(g)$ into a focus tier $(g, h)$, until recombining with a morpheme Q in the root clause at LF, as in (6). Crucially, this analysis suggests that the interpretation of wh-operators does not involve any movement.

(5) a. $\quad\left[[\text { TP Ram ate } \boldsymbol{w h a t}]^{g, h}=\right.$ Ram ate $\mathrm{h}(1)$

b. $\quad \llbracket[$ TР Ram ate $\boldsymbol{w h a t}] \rrbracket^{g}=$ undefined

(6) $\llbracket\left[\mathrm{Q}_{1}\left[\right.\right.$ Ram ate what $\left.\left._{1}\right]\right] \rrbracket^{g}=\lambda p \exists x[p=\lambda w$. Ram ate $x$ in $w]$.

One advantage of the FA approach is that it provides a natural explanation for intervention effects, which are observed in many wh-in-situ configurations (Beck 2006). Intervention effects are the unacceptability that arises when an in-situ wh-operator appears within the scope of a focus-sensitive operator, demonstrated in the sentences in (7) and (8). These sentences are ungrammatical, because the in-situ wh-operator appears within the scope of the intervener 'only'. According to Beck (2006), intervention effects arise because the focus-sensitive operator cannot combine with the constituent containing the in-situ $w h$-operator, since the ordinary semantic value of this constituent is undefined, demonstrated in (9).

* John- $h i \quad$ kyaa khariide-gaa?

John-only what buy-FUT

'What will only John buy?'

(Hindi, Malhotra 2009)

* Minsu-man nuku-lûl po-ass-ni?

Minsu-only who-ACC see-Pst-Q

'Who did only Minsu see?'

(Korean, Beck 2006)

(9) a. $\quad \llbracket\left[\right.$ buy what $\left.\left.{ }_{1}\right]\right]^{g}=$ undefined

b. $\quad \llbracket[$ buy what 1$] \rrbracket^{g, h}=\lambda w \cdot \lambda x \times$ bought $\mathrm{h}(1)$ in $w$

c. $* \llbracket$ only John $\rrbracket^{g}\left(\llbracket[\right.$ buy what 1$\left.] \rrbracket^{g}\right)$

1.2. The PUZZLE IN NEWARI. Generally, the CM and FA approaches are understood as alternative analyses for analyzing the scope of in-situ wh-operators. If in some configuration, an in-situ wh-operator fails to take sentential scope, this may be understood as arising from (island) constraints on covert movement, or by intervention effects constraining focus composition. However, our Newari data show a different pattern: neither island effects or intervention effects occur in matrix clauses, whereas both occur in certain embedded clauses. We will lay out the puzzle in this section and explain this matter in detail in Section 2 and 3, and suggest an account by combining the two approaches in Section 4.

First, intervention effects are not observed for in-situ wh-operators in Newari matrix clauses. In contrast to the Hindi and Korean examples in (7) and (8), Newari wh-operators may take sentential scope over a focus-sensitive operator in matrix clauses, demonstrated in (10).

(10) Rām-na-caka chu na-u?

Ram-ERG-only what eat-PST

'What did only Ram eat?' 
We suggest that the wh-operator takes scope through $\mathrm{CM}$ in this case, given the lack of intervention effect.

Although we do not observe intervention effects in matrix clauses, we do find them in embedded clauses. In (11a), a wh-operator may take either wide or narrow scope in an embedded clause. However, as shown in (11b) the wide-scope reading is blocked when the wh-operator is in the scope of another focus operator.

$$
\begin{aligned}
& \text { a. Sitā-m [CP Rām-na chu na-u (dhakā)] dhā-u } \\
& \text { Sita-ERG Ram-ERG what eat.PST COMP say-PST } \\
& \text { 'Sita said what Ram ate.' } \\
& \text { 'What did Sita say that Ram ate?' } \\
& \text { b. Sitā-ṃ [CP Rām-na-caka chu na-u (dhakā)] dhā-u } \\
& \text { Sita-ERG Ram-ERG-only what eat.PST COMP say-PST } \\
& \text { 'Sita said what only Ram ate.' } \\
& \text { *'What did Sita say that only Ram ate?' }
\end{aligned}
$$

Second, wh-in-situ not sensitive to traditional island constraints (e.g., relative clause islands, complex NP islands, comparative clauses, etc.), when not embedded in a verbal-argument CP. For example, the sentence in (12) has a relative clause, but the $w h$-operator takes wide scope regardless. Thus, no island effects are observed, which is unexpected on a CM analysis.

$$
\begin{aligned}
& \text { Rām-na [RC Su-na dā ma] guru nāplā-u? } \\
& \text { Ram-ERG who-ERG hit CL teacher meet-PST } \\
& \text { 'Which person } x \text {, Ram met the teacher } y \text { that } x \text { hit } y \text { ?' }
\end{aligned}
$$

By contrast, we find that $w h$-operators embedded in a relative clause in a verbal-argument $\mathrm{CP}$ are ungrammatical, as shown in (13).

* Ākās-ām [CP Rām-na [RC su-na dā ma] guru nāplā-u] dhā-u? Akash-ERG Ram-ERG who-ERG hit CL teacher meet-PST say-PST

'Who is the person $x$, such that Akash said that Ram met the teacher $x$ hit?'

Given that there is no clear focus-sensitive operator in this sentence, we argue that this is an instance of an island violation for covert movement.

The pattern that we seek to explain is summarized in Table 1. On most accounts of wh-in-situ configurations, we do not expect island sensitivity and intervention to co-pattern in this way. In this paper, we investigate the following questions: 1) Why does the distribution of wh-phrases determine the constraints that they are sensitive to? 2) Why do we not observe traditional island constraints on covert movement in Newari? 3) Why does Newari exhibit these patterns, but not previously studied languages (Mandarin Chinese, Japanese, Hindi, ... )?

\begin{tabular}{llll} 
Clausal Type & Structure & Island effect & Intervention effect \\
\hline Matrix clause & {$[$ M-CP $[$ Adj-CP $\ldots w h \ldots]]$} & No & No \\
V-complement CP & $[$ М-CP V [Arg-CP $\ldots w h \ldots]]$ & Yes & Yes
\end{tabular}

Table 1 The existence (and non-existence) of the two effects in different clausal types

1.3. OUR PROPOSAL. We propose that Newari permits either covert movement (CM) or focus alternatives composition (FA) to fix the scope of a wh-operator in matrix clauses 
(non-verbal-argument CPs), as shown in (14). This offers an account for why neither of the effects are observed in matrix clauses. When FA is blocked by an intervener, the wh-operator can still take the scope via CM, and vice versa. When CM is blocked by an island, FA will become available for the wh-operator to take scope.

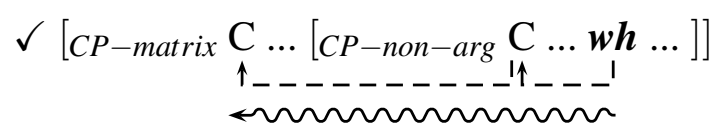

We also propose that Newari only allows the FA strategy for in-situ wh-operators in verbal-argument CPs, as in (15). We will show some evidence to support this analysis in the next two sections, and then discuss a complex case of a non-verbal-argument $\mathrm{CP}$ embedding in a verbal-argument $\mathrm{CP}$, where both FA and CM may be deployed.

$$
\checkmark[C P-\arg C \ldots[C P-\arg C \ldots w h \ldots]]
$$

2. Non Verbal-Argument CPs. In this section, we examine the behavior of in-situ wh-operators in matrix clauses, and embedded clauses that are not arguments to verbs. We demonstrate that both FA and CM strategies may be used in these contexts.

As described above, Newari is typically a wh-in-situ language, i.e., wh-operators appear in their canonical position and take sentential scope, as demonstrated in (16a) and (16b). Wh-operators are homophonous with indefinite pronouns, although they may be assigned a higher tone when interpreted as a $w h$-operator. Additionally, wh-operators may scramble to the beginning of the clause, as demonstrated in (17a). This is improved if the $w h$-operator is D-linked, shown in (17b).
a. Rām-na chu na-la
Ram-ERG what eat-PST
'Ram ate something.'
'What did Ram eat?'

b. Su-na am na-la

Who-ERG mango.ABS eat-PST

'Someone ate mangos.'

'Who ate mangos?'
a. \#Chu Rām-na _ na-la?
what Ram.ERG eat-PST
'What did Ram eat?'
b. Gupati ạ̣ Rām-na _ na-la?
which mango Ram-ERG eat-PST
'Which mango did Ram eat?'

As mentioned in the previous section, we propose that $w h$-operators in matrix clauses may either use FA or CM strategies. First, we do not observe intervention effects, either for argument $w h$-operators, as demonstrated in (10), or for adjunct $w$ h-operators, demonstrated in (18). In these sentences, the wh-operators are c-commanded by the focus operator caka 'only'. If the wh-operator was interpreted with sentential scope through an FA strategy, then these sentences would be predicted to be ungrammatical. Therefore, we propose that the CM strategy is necessary for these configurations. 
Rām-na-caka chæ ạ̣ na-u?

Ram-ERG-only why mango.ABS eat-PST

'Why did only Ram eat a mango?'

Next, we turn our attention to adjunct clauses adjoined in matrix clauses. We investigate island sensitivity for in-situ wh-operators. Huang (1982) argues that in-situ adjunct wh-operators are typically ungrammatical in traditional island configurations - relative clauses, adjunct clauses, comparative clauses, etc. As the example shows in (19), the wh-operator weishenme ('why') is sensitive to the complex NP constraints. However, there is an asymmetry between $w h$-adjuncts and $w h$-arguments in Mandarin Chinese. Wh-arguments are not sensitive to island constructions, demonstrated in (20).
*Qiaofeng xihuan [CP Botong weishenme xie de] shu? Qiaofeng like Botong why write de book
'For reason $x$, such that Qiaofong like the book that Botong wrote for $x$ ?' (Mandarin)
(20) Qiaofeng xihuan [CP Botong gei shui xie de] shu?
Qiaofeng like Botong give who write de book
'For which person $x$, such that Qiaofong like the book that Botong wrote to $x$ ?'

In Newari, we find no sensitivity to traditional islands for in-situ wh-operators. We find that both argument $w h$-operators, as in (21) and (22), and adjunct wh-operators, as in (23), may take wide scope from relative clauses, comparative clauses, and adjunct clauses.

(21) Rām-na [NP [RC su-na dā ma] guru] nāplā-u?

Ram-ERG who-ERG hit CL teacher met-PST

'For which person $x$, Ram met the teacher $y, x$ hit $y$ ?'

(22) Rām-a [CP su-na bwæṃ wani-u shyā yaku] swimming ya-i.

Ram-ERG who-ERG run go-PST than more swimming do-NONPST

'For which person $x$, Ram swims more than $x$ runs?'
[ADJ Rām-
Sitā-ta
gena pāy-u
$\lim ]$
wi-to
mhiphusi swama?
Ram-ERG Sita-DAT how blame-PST because, 3.SG-DAT sad
PROG

'For which way $x$, because Ram blamed Sita in $x$ way, she feels sad?'

To account for these facts, we could suggest that the wh-operator takes sentential scope through an FA strategy. If so, we predict no island sensitivity, as observed above. However, we then predict that we should find intervention effects for these configurations. Surprisingly, as we show below, this prediction is not borne out. Thus, the wh-operator must take scope through a CM strategy, and we conclude that relative clauses, comparative clauses, and adjunct clauses are not islands for covert movement of wh-operators.

Importantly, we find no intervention effects for wh-operators in these positions. In (24), we find that suna 'who.ERG' takes wide scope, even though it is interpreted in the scope of caka 'only'. This implies that suna does not take sentential scope through an FA strategy. Instead, we infer that it fixes its scope through the CM strategy. Similar findings are demonstrated in (25).
Rām-na-caka [NP [CP su-na dā ma] guru] nāplā-u?
Ram.ERG-only who-ERG hit CL teacher meet-PST
'For which person $x$, Ram met the teacher $y, x$ hit $y$ ?' 
Rām-a-caka [CP su-na bwæm wani-u shyā yaku] swimming ya-i.

Ram-ERG-only who-ERG run go-PST than more swimming do-NONPST

'For which person $x$, Ram swims more than $x$ runs?'

In this section, we argued that wh-operators must covertly move in Newari, given that there are no intervention effects observed for matrix $w h$-in-situ configurations. Furthermore, we found no evidence of island effects for covert movement, in many traditional island configurations, specifically, relative clauses, comparative clauses, and adjunct clauses.

3. Verbal-Argument CPs. We now turn our attention to the verbal-argument CP structures. In this section, we examine whether island effects or intervention effects are observed in this kind of structure, and whether argument $w h$-operators or adjunct $w h$-operators show different profiles.

3.1. InTERVENTION EFFECTS IN VERBAL-ARGUMENT CPS. Generally, argument wh-operators may take sentential scope from a verbal-argument $\mathrm{CP}$ :

$$
\begin{aligned}
& \text { Sitā-na [CP su-na am na-u dhāyā] si-la? } \\
& \text { Sita-ERG who-ERG mango.ABS eat-PST COMP know-NONPST } \\
& \text { 'Who did Sita know ate the mango?' }
\end{aligned}
$$

However, unlike matrix clauses or non-argument embedded clauses, we do observe intervention effects in verbal-argument CPs. In (27), we find that the sentential scope interpretation of chu 'what' is blocked. Instead, $c h u$ 'what' must be interpreted with embedded scope. Similar findings are demonstrated with (27b) for the adjunct wh-operator chce 'why'. We attribute this obligatory low-scope induced by the addition of the focus operator caka 'only' to an intervention effect.
a. Sitā-ṃ [cP Rām-a-caka chu na-u (dhakā)] dhā-u
Sita-ERG Ram-ERG-only what eat.PST COMP say-PST
'Sita said what only Ram ate.'
* 'What did Sita say that only Ram ate?'
b. Sitā-m [CP Rām-a-caka chæ ạ̣ na-u (dhakā)] dhā-u
Sita-ERG Ram-ERG-only why mango.ABS eat.PST COMP say-PST
'Sita said why only Ram ate mango.'
* 'Why did Sita say that only Ram ate mango?'

We also find that a sentential scope interpretation is available if the wh-operator overtly scrambles above the focus-operator, as in (28). This supports our analysis, since overt movement has been independently shown to ameliorate intervention effects (Beck 2006). ${ }^{1}$
a. Sitā-ṃ [CP chu Rām-a-caka na-u (dhakā)] dhā-u
Sita-ERG what Ram-ERG-only eat.PST COMP say-PST
\#'Sita said what only Ram ate.'
'What did Sita say that only Ram ate?'
b. Sitā-ṃ [cP chæ Rām-a-caka _ aṃ na-u (dhakāa)] dhā-u
Sita-ERG why Ram-ERG-only mango.ABS eat.PST COMP say-PST
\#'Sita said why only Ram ate mango.'
'Why did Sita say that only Ram ate mango?'

\footnotetext{
${ }^{1}$ Overtly scrambling the $w h$-operator makes embedded scope interpretations much more difficult to access. We do not account for this fact here. However, this may be related to the fact that, in general, scrambling $w h$-operators strongly prefer sentential scope.
} 
Furthermore, verbal-argument CPs can be fronted. If so, the $w h$-operator can take sentential scope, as in (29). Moving a verbal-argument $\mathrm{CP}$ over an intervener can ameliorate an intervention effect. In (30a), we find obligatory embedded scope for $c h u$ 'what', which we attribute to an intervention effect induced by caka 'only'. However, moving the CP to the front of the clause permits both sentential and embedded scope, as shown in (30b).

[CP Rām-a chu na-u (dhakā)] Sitā-ṃ dhā-u

Ram-ERG what eat.PST COMP Sita-ERG say-PST

'Sita said what Ram ate.'

'What did Sita say that Ram ate?'
a. [cP Rām-a-caka chu na-u (dhakā)] Sitā-ṃ dhā-u
Ram-ERG-only what eat.PST COMP Sita-ERG say-PST
'Sita said what only Ram ate.'
*'What did Sita say that only Ram ate?'
b. [CP Chu Rām-a-caka _ na-u (dhakā)] Sitā-ṃ dhā-u what Ram-ERG-only eat.PST COMP Sita-ERG say-PST
'Sita said what only Ram ate.'
'What did Sita say that only Ram ate?'

We find the same result for adjunct $w h$-operators, shown in (31a). An intervener forces the wh-operator chae 'why' to take embedded scope. However, moving the verbal-argument $\mathrm{CP}$ to the front of the clause permits sentential scope.
a. [cP Rām-a-caka chæ oṃ na-u (dhakā)] Sitā-ṃ dhā-u
Ram-ERG-only why mango.ABS eat.PST COMP Sita-ERG say-PST
'Sita said why only Ram ate mango.'
*'Why did Sita say that only Ram ate mango?'
b. [CP Chæ Rām-a-caka _ om nạ na-u (dhakā)] Sitā-ṃ dhā-u
why Ram-ERG-only mango.ABS eat.PST COMP Sita-ERG say-PST
'Sita said why Ram ate mango.'
'Why did Sita say that Ram ate mango?'

So far, we have only examined sentences in which the intervener is in the same clause as the $w h$-operator. Similar patterns obtain when the intervener is in the matrix clause. In (32a), the addition of an intervener results in an ungrammatical sentence.
a. Rām-a [CP [CP Sitā-ṃ chu na-u] sāyl-ạ̣ dhā-u] swace yā-u
Ram-ERG Sita-ERG what eat.PST Sayal-ERG say-PST think do.PST
'What did Ram think that Sayal said that Sita ate?' 2
b. *Rām-a-caka [CP [CP Sitā-ṃ chu na-u] sāyl-ạ̣ dhāu] swace yā-u Ram-ERG-only Sita-ERG what eat.PST Sayal-ERG say.PST think do.PST 'What did only Ram think that Sayal said that Sita ate?'

If this results from an intervention effect, then we again predict that moving the clause above the intervener should result in the availability of sentential scope, due to amelioration of the intervention effect. This prediction is confirmed in (33). Moving the most deeply embedded

\footnotetext{
${ }^{2}$ We do not have an explanation for why double center-embedding does not yield narrow scope in this sentence, or in (33)
} 
clause (Sitām chu nau Sita-ERG what eat.PST 'Sita ate what') to the front of the sentence yields sentential scope.

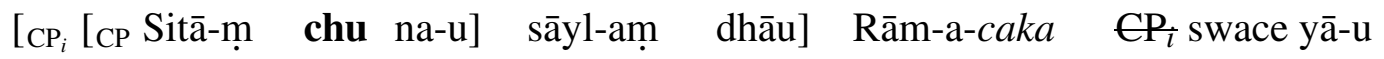

Sita-ERG what eat.PST Sayal-ERG say.PST Ram-ERG-only think do.PST

'What did only Ram think that Sayal said that Sita ate?'

To summarize, we demonstrate that we consistently get intervention effects for $w h$-operators embedded in verbal-argument CPs, as sketched in (34), unlike matrix clauses or in other embedded CPs. On a CM analysis, these findings are surprising, since covert movement should ameliorate intervention effects in the LF representation. In this paper, we argue that, in general, Newari employs both FA and CM strategies for in-situ wh-operators, and verbal-argument CPs must be islands for covert movement in Newari.

(34) Intervention Effects in FA of argument CPs, account for Sentence (27) and (32b):
a. $*\left[{ }_{M-C P} \mathrm{C}[\arg -C P \mathrm{C} \ldots[\arg -C P \mathrm{C} \ldots\right.$ FOCUS ... wh ... $\left.]]\right]$
זחר
b. * ${ }_{M-C P} \mathrm{C}[\arg -C P \mathrm{C} \ldots$ FOCUS ... $\left.[\arg -C P \mathrm{C} \ldots \boldsymbol{w h} \ldots]]\right]$

However, there are some apparent counterexamples to our proposal. On our analysis, wh-operators embedded in verbal-argument CPs must rely on an FA strategy to be interpreted with sentential scope. This is because covert movement out of verbal-argument CPs is blocked. If so, then we predict that there should be no sensitivity to traditional island configurations, since only (covert) movement is sensitive to island constraints, by hypothesis, and because we have argued that traditional island constraints do not apply to covert movement in Newari. However, as demonstrated in (35) and (36), it is ungrammatical to have a $w h$-operator in a relative clause embedded in a verbal-argument CP. This might be interpreted as an island violation, given that relative clauses and adjunct clauses are typically islands. If so, then this appears to contradict our proposal that relative clauses and adjunct clauses are not islands in Newari, and that only the FA strategy is employed for wh-operators embedded in verbal-argument CPs, as sketched in (37).

* Ākās-ām [CP Rām-a [NP [RC su-na dā ma] guru] nāplā-u] dhā-u?

Akash-ERG Ram-ERG who-ERG hit CL teacher meet-PST say-PST

'For which person $x$, Akash said that Ram met the teacher $y$ that $x$ hit $y$ ?'

*Rām-a [CP [ADJ ji-ṃ gana ma wạ̣-u liṃ], ji fel ju-la] dhā-u Ram-ERG 1.SG-ERG where NEG go-PST because, 1.SG fail happen-PST say-PST 'For which place $x$, Ram said that, because I didn't go to $x$, I failed?'

(37) Fail to covertly move $w h$-operator out of the argument $\mathrm{CP}$ boundary:

$$
*[M-C P \mathrm{C}[\arg -C P \mathrm{C} \ldots[\operatorname{adj}-C P \mathrm{C} \ldots \boldsymbol{w h} \ldots]]]
$$

Since Newari employs both FA and CM strategies, it is unclear why they may not be applied on after the other (CM after FA) for the wh-operator to take sentential scope, as suggested for English by (Kotek \& Hackl 2013), sketched in (38). Such a derivation appears to be unavailable for Newari wh-in-situ.

(38) Model of English multi-wh-questions:

$$
\checkmark[M-C P \text { wh ...C }[\underbrace{\arg -C P} \mathrm{C} \ldots[\operatorname{adj}-C P \mathrm{C} \ldots \boldsymbol{w h} \ldots]]]
$$




\section{Towards to an Account: A combination of Covert Movement and Focus Alternatives in}

Newari. In this paper, we proposed that, in Newari, (1) the mechanism for fixing $w h$-scope depends on the configuration that the $w h$-operator surfaces in, and (2) verbal-argument CPs are islands for covert movement, but not relative clauses, comparative clauses, or adjunct clauses. Given the absence of intervention effects in matrix clauses, we proposed that $w h$-operators covertly move in Newari. However, in principle, FA may also be available. Thus, the sentence in (39) may be syntactically ambiguous as in (40a) and (40b). We propose that Universal Grammar permits $w h$-operators to take scope either by either the CM or FA strategies.

Rām-na chu na-la?

Ram-ERG what eat-PST

'What did Ram eat?
a. Covert movement LF:
[CP C Rām-na chu na-la ].
b. Focus alternatives composition LF: [CP Q Rām-na chu na-la ]. Q Q R n

If so, we reasoned that the presence of intervention effects for $w h$-operators in verbal-argument CPs must arise because the CM strategy is blocked, i.e., verbal-arguments are islands for covert movement. At this point, we do not have a clear explanation for why this should be the case in Newari, but not in many other well-studied languages, such as Mandarin, Japanese, or Hindi. One possibility is that these constraints follow from the syntax of evidentiality in Newari. Newari uses a "conjunct/disjunct" agreement system, in which the verb agreement is determined by whether the subject is coreferential with the perspective-holder (Zu 2015, Coppock \& Wechsler 2016). Following Zu (2015), we assume verbal agreement is controlled by a null pronoun in Spec, CP that is coindexed with the perspective holder. Conjunct agreement occurs when the grammatical subject and this pronoun are co-indexed, and disjunct agreement occurs when they are contra-indexed:

$$
\begin{aligned}
& \text { a. Wо-ṃ }{ }_{i} \text { [ср } \operatorname{pro}_{i}[\text { тр lā na-e dhakā] dhāla } \\
& \text { He.ERG meat eat-CONJ COMP said } \\
& \text { ' } \mathrm{He}_{i} \text { said that he }{ }_{i} \text { will eat meat.' } \\
& \text { b. Wo-ṃ }{ }_{i} \text { [ср } \text { pro }_{j}[\text { те lā na-i dhakā] dhāla } \\
& \text { He.ERG meat eat-DISJ COMP said } \\
& \text { ' } \mathrm{He}_{i} \text { said that he }{ }_{j} \text { will eat meat.' }
\end{aligned}
$$

Newari (Hargreaves 1991)

If this account is on the right track, then it may be that this perspective-taker pronoun in Spec, $\mathrm{CP}$ may block the Spec,CP escape hatch. In other words, the availability of conjunct/disjunct agreement in Newari may induce a subjacency violation for covert movement from the verbal-argument CP. This appears to contradict the findings from Huang (1982), however, and thus needs to be examined in more detail in future research.

Relatedly, we are forced to say that traditional islands (CNPC, relative clauses, adjunct clauses) are not islands for covert movement in Newari, although verbal-argument CPs are. However, overt movement (e.g., relativization) appears to pattern in the expected ways extraction from traditional islands is unacceptable, and extraction from embedded clauses, as showing in (42a) and (42b), while (43) seems to be better than the former ones. 
(42) a. *Rām-na [NP [RC [NP [RC $t_{i}$ khaṃ-u ma] masā] Nepali kha ma] guru $\left.{ }_{i}\right]$ nāplā-u Ram-ERG see-PST CL child Nepali COP CL teacher meet-PST 'Ram met the teacher $x$ that the child $y$ that saw $x$ was Nepali.'

b. *Ji-ṃ [NP [CP [Adj wa $t_{i}$ wa-la liṃ] Nepal-bhāsā bwani-u] skul $i_{i}$ ] wa-na I-also $\quad 3 . S G$ went because Newari-language study-CL school went 'I also went to the school $x$ that Ram studied Newari because he went to $x$.'

*Ram [CP-adj Sita-m [CP-arg w-ito $t_{i}$ ya dhāka] dhā-ma] guru nāplā-u
Ram Sita-ERG $\quad$ she-DAT like COMP say-CL teacher meet-PST
'Ram met the teacher that Sita said that she liked.'

Finally, this approach over-generates. Recall that $w h$-operators in an adjunct clause embedded in a verbal-argument $\mathrm{CP}$ cannot take sentential scope, which we diagnosed as an island effect. However, if a focus alternative analysis is always available in principle, this sentence is predicted to be grammatical. Thus, we need some way of blocking focus alternatives in these contexts, even though it seems necessary in other contexts, as (44) shows:

$$
\begin{aligned}
& \text { * ākās-ām [CP Rām-a [NP [RC su-na dā ma] guru] nāplā-u] dhā-u? } \\
& \text { Akash-ERG Ram-ERG who-ERG hit CL teacher meet-PST say-PST } \\
& \text { 'For which person } x \text {, Akash said that Ram met the teacher } y \text { that } x \text { met } y \text {.' }
\end{aligned}
$$

Despite these shortcomings, the evidence in Newari suggests that covert movement and focus alternatives are both available, each with their own locality constraints. We argue that the findings that we've described follow as a conspiracy from these constraints, plus independently-motivated grammatical properties (i.e., conjunct/disjunct agreement).

5. Conclusion In this paper, we demonstrated that Newari non-argument CPs (matrix clauses and adjunct clauses) do not show intervention effects or island effects, while intervention effects are observed in the verbal-argument $\mathrm{CPs}$, and island effects appear when adjunct clauses are embedded inside of the verbal-argument CPs. We propose both covert movement and focus alternative analysis account for the array of scopal interpretations for in-situ wh-configurations. For future work, we will investigate the issue with other interveners in this language. Additionally, we plan to investigate when interveners result in ungrammaticality in Newari, as opposed to obligatorily embedded scope. Finally, we seek to clarify why verbal-argument CPs are islands for covert movement, and why the patterns observed in Newari are not found in better-studied languages. 
A. Extra Data. Examples of wh-in-situ exhibiting no island effects of complex NP construction in non-argument CP clause. In (45) and (46), 'chu' and 'guble' take wide scope, and they are grammatical.

Rām-na [NP [CP Sitā-na chu ne-i dhayu] tathaya] sy-u?

Ram-ERG Sita-ERG what eat-NON-PST COMP news know-PST

'For which thing $x$, such that Ram know the news that Sita will eat $x$ ?'

Rām-a [NP [cP Sitā-m guble am na-u $\quad$ (wa) halā $]$ shy-u?

Ram-ERG Sita-ERG when mango.ABS eat-PST that rumor know-PST

'For which time $x$, such that Ram know the rumor that Sita ate mango at $x$ time?'

Examples of wh-in-situ exhibiting island effects of complex NP construction in argument CP clause. In (47) and (48), 'chu' and 'guble' cannot take wide scope, and they are ungrammatical.

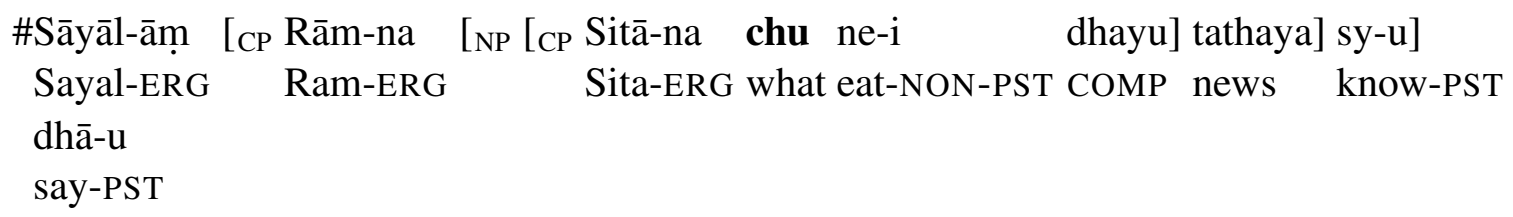

Intended: 'For which $x$, such that Sayal said that Ram know the news that Sita will eat?'

(48) *ākās-ām [CP Rām-a [CP Sitā-ṃ guble ạ̣ $\quad$ na-u $] \quad$ (wa) halā shy-u] Akash-ERG Ram-ERG Sita-ERG when mango.ABS eat-PST that rumor know-PST swace yato?

think do.PST

Intended: 'When did Akash think Ram know the rumor that Sita ate mango?

Examples of wh-in-situ exhibiting no island effects of relative clauses inside of non-argument $C P$ clause, as in (49), the wh-operator 'chu' takes wide scope, while exhibiting island effects in inside of argument CP clause, as it does not take wide scope in (50).

(49) Rām-a [NP [RC su-na dā ma] guru] nāplā-u?

Ram-ERG who-ERG hit CL teacher meet-PST

'For which person $x$, such that Ram met the teacher who $x$ hit?'

(50) *Ākās-ām [CP Rām-a [NP [RC su-na dā ma] guru] nāplā-u] dhā-u?

Akash-ERG Ram-ERG who-ERG hit CL teacher meet-PST say-PST

'For which person $x$, such that Akash said that Ram met the teacher who $x$ hit?'

Examples of wh-in-situ exhibiting no island effects of comparative clause inside of non-argument $C P$ clause, as in (51), the wh-operator 'su-na' takes wide scope, while exhibiting island effects in inside of argument CP clause, as it does not take wide scope in (52).

(51) Rām-a [CP su-na bwæṃ wani-u shyā yaku] swimming ya-i.

Ram-ERG who-ERG run go-PST than more swimming do-NonPst.

'For which person $x$, such that Ram swims more than $x$ runs?'

(52) *ākās-āṃ [CP Rām-a [CP su-na bwæṃ wani-u shyā yaku] swimming Akash-ERG Ram-ERG who-ERG run go-PST than more swimming ya-i] dhā-u?

do-NONPST say-PST.

Intended: 'For which person $x$, such that Akash said Ram swims more than $x$ runs?' 
Examples of wh-in-situ exhibiting no island effects of 'because'-clause inside of non-argument CP clause, as in (53), the wh-operator 'gana' takes wide scope, while exhibiting island effects in inside of argument CP clause, as it does not take wide scope in (54).

[ADJ ji-m gana ma wam-u lim], ji fel ju-la.

1.SG-ERG where NEG go-PST because, 1.SG. fail happen-PST

'For which place $x$, such that because I didn't go $x$, I failed (the test)?'

*Rām-a [CP [ADJ ji-m gana ma wam-u lim], ji fel ju-la] dhā-u
Ram-ERG
'For which place $x$, such that Ram said because I didn't go x, I failed (the test)?'

Examples of wh-in-situ exhibiting no island effects of 'beforelafter'-clause inside of non-argument CP clause, as in (55), the wh-operator 'chu' takes wide scope, while exhibiting island effects in inside of argument CP clause, as it does not take wide scope in (56).

[ADJ Sāyāl-āṃ chu he-i nyṃ/daṃkā] Sitā pasal-e wan-i.

Sayal-ERG what bring-NONPST before/after Sita store-LOC go-NONPST

'For which thing $x$, such that before Sayal brings $\mathrm{x}$, Sita will go to the store.'

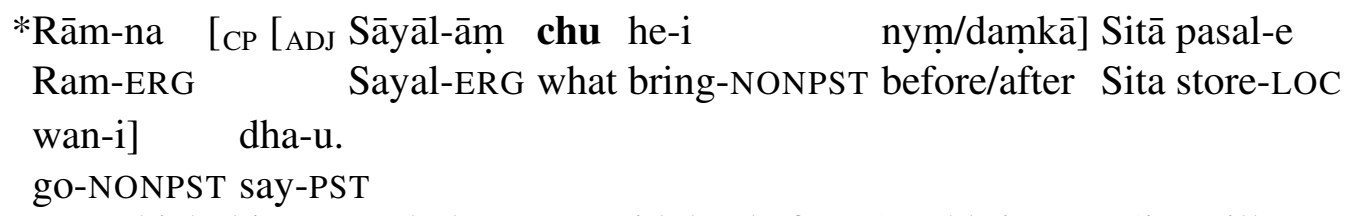

'For which thing $x$, such that Ram said that before Sayal brings x, Sita will go to the store.'

Examples of wh-in-situ exhibiting no island effects of ' $w$ h'-clause inside of non-argument CP clause, as in (57), the wh-operator 'suito' takes wide scope, while exhibiting island effects in inside of argument CP clause, as it does not take wide scope in (58).

(57) Rām-a [CP Sāyāl-ām su-ito dā-lā dhaya] bihchar yāna-swana?

Ram-ERG Sayal-ERG who.DAT hit-Q COMP] wonder do.PST-PROG

'Ram is wondering whether Sita hit whom?'

(58) *Sitā-na [CP Rām-a [CP Sāyāl-ām sụ su-ito dā-lā dhaya] bihchar yāna-swana]

Sita-ERG Ram-ERG Sayal-ERG who.DAT hit-Q COMP] wonder do.PST-PROG

dhā-u?

say-PST

'Sita said Ram is wondering whether Sita hit whom?'

\section{References}

Bayer, Josef. 2006. Wh-in-situ. In Martin Everaert (ed.), The Blackwell companion to syntax, $376-438$.

Beck, Sigrid. 2006. Intervention effects follow from focus interpretation. Natural Language Semantics 14(1). 1-56.

Cheng, Lisa Lai-Shen. 2009. Wh-in-situ, from the 1980s to now. Language and Linguistics Compass 3(3). 767-791.

Coppock, Elizabeth \& Stephen Wechsler. 2016. The proper treatment of egophoricity in Kathmandu Newari. Paper presented at Semantics and Philosophy in Europe. Cambridge University. 
Hamblin, Charles L. 1973. Questions in Montague English. Foundations of language 10(1). 41-53.

Hargreaves, David J. 1991. The concept of intentional action in the grammar of Kathmandu Newari: University of Oregon dissertation.

Huang, CT James. 1982. Move wh in a language without wh movement. The linguistic review 1(4). 369-416.

Karttunen, Lauri. 1977. Syntax and semantics of questions. Linguistics and philosophy 1(1). 3-44.

Kotek, Hadas \& Martin Hackl. 2013. A new syntax for multiple wh-questions: Evidence from real time sentence processing. Manuscript, MIT.

Malhotra, Shiti. 2009. Intervention effects and wh-movement. University of Pennsylvania Working Papers in Linguistics 15(1). 16.

Soh, Hooi Ling. 2005. Wh-in-situ in Mandarin Chinese. Linguistic Inquiry 36(1). 143-155.

Yang, Barry Chung-Yu. 2012. Intervention effects and wh-construals. Journal of East Asian Linguistics 21(1). 43-87.

$\mathrm{Zu}$, Vera. 2015. Competition and obviation from French to Newari. Proceedings of NELS 46. 329-342. 